\title{
Health related quality of life in chronic kidney disease; a descriptive study in a rural Sri Lankan community affected by chronic kidney disease
}

Sameera Senanayake ${ }^{1 *}$ (D, Nalika Gunawardena ${ }^{2}$, Paba Palihawadana', Shanika Senanayake ${ }^{3}$, R. Karunarathna ${ }^{4}$, Priyantha Kumara ${ }^{4}$ and Sanjeewa Kularatna ${ }^{3}$ (D)

\begin{abstract}
Introduction: The current epidemic of chronic kidney disease (CKD) in Sri Lanka is ascribed to the exponential increase in the number of CKD patients, which cannot be attributed to any known etiology (CKDu). The aim of this study is to describe the health related quality of life (HRQOL) and the associated factors among CKD/CKDu patients in a rural district in Sri Lanka.

Methods: A community based cross-sectional study included 1174 CKD/CKDu patients. Kidney Disease Quality of Life-Short Form was used to assess the HRQOL, while Centre for Epidemiologic Studies Depression Scale, General Health Questionnaire (GHQ) 12 and CKD Symptom Index - Sri Lanka were used to assess presence of depression, psychological distress and symptom burden respectively. Three summary scores; kidney disease (KDSC), physical (PCS) and mental (MCS) are derived from Kidney Disease Quality of Life-Short Form (KDQOL-SFTM).

Results: Mean age of the study population was 58.3 years (standard deviation (SD) 10.7). Median KDSC (58.4; inter-quartile range (IQR) 54.2-63.4), was higher than the median scores of PCS (35.0; IQR 26.2-41.9) and MCS (58.4; IQR 54.2-63.4). Multiple linear regression revealed low income, advanced stages of CKD, symptom burden, being positive for depression and psychological distress were significantly associated with low HRQOL.

Conclusion: The HRQOL of the CKD patients in this rural Sri Lankan population was found to be poor. Superior socioeconomic status, less physical and psychological symptom burden were found to be independently associated with better HRQOL. Periodical screening of the CKD patients for depression and psychological distress and measures to alleviate symptom burden seem to be important to improve the HRQOL of these patients.
\end{abstract}

Keywords: Chronic kidney disease, Quality of life, Sri Lanka, Chronic kidney disease of unknown etiology

\section{Introduction}

Interest in the concept of health related quality of life (HRQOL) began in the early seventies and has increased over the last 20 years, becoming one of the central goals of patient management. HRQOL is not a universal phenomenon and there is no single definition to

* Correspondence: sam197902@gmail.com

${ }^{1}$ Epidemiology Unit, Ministry of Health, Colombo, Sri Lanka

Full list of author information is available at the end of the article describe all its facets. World Health Organization Quality of Life Group (WHOQOL) in 1994 defined quality of life (QOL) as "an individual's perception of their position in life in the context of culture and value systems in which they live and in relation to their goals, expectations, standards and concerns" [1]. However, HRQOL refers to QOL in the context of disease and health. Health is considered a multidimensional concept, thus, HRQOL is also multidimensional and incorporates

C C The Author(s). 2020 Open Access This article is licensed under a Creative Commons Attribution 4.0 International License, which permits use, sharing, adaptation, distribution and reproduction in any medium or format, as long as you give appropriate credit to the original author(s) and the source, provide a link to the Creative Commons licence, and indicate if changes were made. The images or other third party material in this article are included in the article's Creative Commons licence, unless indicated otherwise in a credit line to the material. If material is not included in the article's Creative Commons licence and your intended use is not permitted by statutory regulation or exceeds the permitted use, you will need to obtain permission directly from the copyright holder. To view a copy of this licence, visit http://creativecommons.org/licenses/by/4.0/ The Creative Commons Public Domain Dedication waiver (http://creativecommons.org/publicdomain/zero/1.0/) applies to the data made available in this article, unless otherwise stated in a credit line to the data. 
domains related to physical, mental and emotional, and social functioning [2]. Therefore HRQOL is a subjective phenomenon usually influenced by expectations, person's experience and beliefs [3].

Over the years, chronic kidney disease (CKD) has emerged as a major public health problem in Sri Lanka. Exact prevalence estimates of CKD are not available in Sri Lanka. Medical statistics on hospitalizations and deaths in the state sector hospitals in the country do not present data for CKD but present data on diseases of the urinary system. These statistics indicate that in 2017 diseases of the urinary system was the 6th leading cause of hospitalization in the country accounting up to $4.7 \%$ of total hospital admissions. Diseases of the urinary system was also the 8th leading cause of hospital deaths with a rate of 12.9 per 100,000 population [4]. The corresponding figure for the year 2012 was 12.1 per 100,000 population [5].

Chronic kidney disease is a chronic disease condition and by its progressive and disabling nature, has a significant impact on HRQOL of affected individuals [6]. From the early stages of the disease to its end stage, disabling symptoms, various food and restrictions to social life, fluid restrictions and associated stigma and taboos, affect daily life of the patients. Furthermore, CKD affects the mental well-being which in turn affects the HRQOL of patients. A recent study among CKD patients in Sri Lanka revealed that $75.0 \%$ (95\% CI 72.5-77.5) of participants were psychologically distressed while $65.2 \%$ (95\%CI 62.4-68.0) were depressed [7]. World over, the importance of including HRQOL indicators in the clinical management of CKD patients has been highlighted [8-11]. This has come to the limelight after several studies demonstrated the strong relationship between reduced HRQOL and increased morbidity and mortality [8-11]. Kidney Disease Outcomes Quality Initiative (K/ DOQI), which is the leading organization in developing standards and guidelines pertaining to management of CKD, advises the HRQOL to be evaluated regularly in order to establish baseline function and monitor changes occurring over time as well as to evaluate the effects of various interventions in all patients with glomerular filtration rate (GFR) below $60 \mathrm{ml} / \mathrm{min}$ (stage III) [12]. Further, the Center for Medicare Services in United States has made it a mandatory requisite of routine measurement of HRQOL of all dialysis patients [3].

Chronic kidney disease has become a major health problem in the North Central Province (NCP) of Sri Lanka during the past two decades and this is mainly due to CKD which cannot be attributed to any known etiology [13]. This form of CKD is usually termed Chronic Kidney Disease of uncertain etiology (CKDu). There are records of an exponential increase in the number of cases of CKDu in the NCP since the early 1990's [14]. Though the accurate proportions of known and unknown origin are not available, diseases of the urinary system, which includes CKD, is the leading cause of hospital deaths and the 5th leading cause of hospital admissions in NCP [15]. Research evidence indicates that the CKDu affected patients are mostly young and belong to the low socio-economic class [16]. Research evidence also confirm that the increase in burden of CKD in the past two decades has crippled this community leading to significant physical, psychological and economic hardships [17].

Systematic evaluation of the HRQOL of the CKD/ CKDu patients in the rural districts of NCP has not been carried out to date. This study aims at assessing the disease related quality of life and the associated factors among CKD patients in the Anuradhapura district, a rural district in NCP. Evaluation of HRQOL among CKD/CKDu patients in this community can add new insight into the management of the disease as it allows the quantification of the disease consequences according to the patient's perception and enables adjustment of medical decisions to their physical, emotional, and social needs. Furthermore, understanding the extent to which QOL is affected in patients with CKD, will help facilitate the implementation and evaluation of interventions which favorably impact the wellbeing of the patients.

\section{Methods}

\section{Patient selection}

A population based descriptive cross-sectional study was conducted in the district of Anuradhapura in the North Central Province (NCP) of Sri Lanka. Confirmed CKD patients more than 18 years of age with documented evidence of CKD, living in the Anuradhapura district were included in the study. The study period was from January 2016 to March 2016. Following patients were excluded from the study; patients with previous renal transplantation, critically ill patients and patients who were unable to provide rational information for any reason (e.g.; mental retardation). Informed consent was obtained from the eligible study participants prior to data collection.

The country is divided into 338 preventive healthcare areas, called Medical Officer of Health $(\mathrm{MOH})$ areas. Anuradhapura district has 19 Medical Officer of Health areas and the study was conducted in all the $19 \mathrm{MOH}$ areas. The number of patients to be included from each Medical Officer of Health area was based on probability proportionate to the size of CKD patients registered in each of the Medical Officer of Health area. Simple random sampling method was used to select the required number of participants from each Medical Officer of Health area. The population based CKD register, available at the Provincial Director of Health Services, 
records the patients with a confirmed diagnosis of CKD from renal clinics in hospitals of the NCP since 2003. This register was used as the sampling frame.

\section{Assessment of HRQOL}

Health related quality of life was assessed using the locally validated Kidney Disease Quality Of Life-Short Form (KDQOL-SF ${ }^{\mathrm{mm}}$ ) version 1.3. The instrument was confirmed as having a good construct validity and test re-test reliability [18].

KDQOL-SF has two components; Kidney Disease Specific Component and SF-36. Of the total 81 questions in 19 domains, 43 questions assess 11 kidney disease specific components of HRQOL and SF-36 questionnaire in which the 36 questions assess the general health related HRQOL in eight domains.

The 11 domains of Kidney Disease Specific Component are: symptom/problem list (12 items), effects of kidney disease ( 8 items), burden of kidney disease (4 items), cognitive function (3 items), quality of social interaction (3 items), sexual function (2 items), sleep (4 items), social support (2 items), work status (2 items), patient satisfaction (1 item), and dialysis staff encouragement (2 items). SF-36 includes 36 items that measure eight domains and the eight domains are: physical function (10 items), role limitations caused by physical problems (4 items), role limitations caused by emotional problems (3 items), pain ( 2 items), general health perceptions (5 items), social function (2 items), emotional well-being ( 5 items), and energy/fatigue (4 items). The final item, the overall health rate item, asks the respondents to rate their health on a $0-10$ response scale. Different questions have different answer options, which range from two to seven. When scoring, each question is scored in a scale ranging from 0 (worst health) to 100 (best health). All items in a domain are summed up and averaged to give an average score for each domain which ranges from 0 (worst health) to 100 (best health). Three summary scores; kidney disease summary component (KDSC), physical component summary (PCS) and mental component summary (MCS) are derived from the 19 domain scores of KDQOL-SF ${ }^{\text {six }}$, by averaging the domain scores in respective three summary components. Summary scores range from 0 to 100; the higher the score, the better the HRQOL.

Potential factors associated with HRQOL were conceptualized through review of the literature. Along with many other factors; socio-demographic factors, kidney disease-related factors, psychological burden in terms of depression and psychological distress, the symptom burden due to CKD, and household cost to obtain health services; were identified as specific factors possibly associated with HRQOL and were assessed using the methods described as follow.

\section{Assessment of depression and psychological distress}

Patients were screened for depression and psychological distress by locally validated Sinhalese versions of the Centre for Epidemiologic Studies Depression Scale, CESD [19] and GHQ-12 [20], respectively. CES-D instrument has 20 items and out of the total score of 60 , a score more than 15 is indicative of depression in the local setting with a sensitivity of $84 \%$ and a specificity of $92 \%$. GHQ-12 has a total possible score of 12 . A cut-off value of two or more is recommended to identify psychological distress with a sensitivity of $74 \%$ and a specificity of $71 \%[20]$.

\section{Assessment of symptom burden of CKD patients}

CKD Symptom Index - Sri Lanka (CKDSI-Sri Lanka), which has been locally developed and validated, was used to assess the symptom burden. CKDSI-Sri Lanka was confirmed as having an excellent construct validity and test/re-test reliability [21]. The CKDSI -Sri Lanka consists of a checklist of 25 symptoms. Each one requires a response of 'No' if the patient did not experience the particular symptom during the seven days prior to the time of inquiry and the response 'Yes' if he/she did experience it during that time period. If the response is positive, the patient is then asked to rate the severity of the symptom on a 5-point Likert scale. In assessing the symptom burden, the severity rate of each symptom of 1 to 5 , was treated as a score. Those who did not experience the symptom were given a score of zero. The symptom burden score for each respondent was the sum of the symptom severity scores for each of the symptoms included in the CKDSI-Sri Lanka. The possible score ranged from zero to 125 .

\section{Assessment of household costs of CKD patients}

Questions to assess the household cost were developed by reviewing literature and from inputs from CKD patients and caregivers. The instrument was pre-tested in Polonnaruwa district, a rural district in NCP [22]. Total household costs for the patient were calculated by assessing expenditures incurred for hospital admissions, dialysis and clinic visits; including the cost of transport, food, drugs, investigations, medical equipment and expenses for accompanying persons. Furthermore, expenditures on private medical consultations for treatment by Western medical practitioners, Ayurvedic medical practitioners or any other type of medical practitioners and religious rituals were also included.

\section{Survey administration and data collection}

After patient enrolment, the data collector collected basic demographic data from the patient and administered the instruments; KDQOL-SF, CES-D, GHQ-12, CKDSI-Sri Lanka. Demographic data collected were age, 
gender, comorbidities status and employment status. Clinical, biochemical and treatment-related information was extracted from the patient's personal medical record. The latest available serum creatinine value within three months of data collection was used to calculate the eGFR of the patient. The Modification of Diet in Renal Disease equation was used for this purpose.

Data collection has been done by five Public Health Inspectors working in the CKD unit in the North Central Province who had experience in functioning as data collectors for many local and international studies done among CKD patients. Data collection was mostly done on weekdays considering the fact that most of the study units were expected to be at home, since most are employed in the informal sector. Initially the eligibility of the selected study participants was assessed by the data collectors and if found eligible they were informed the purpose of the study and were invited to participate in the study. Further, the voluntary nature of participation and the opportunity to decline participation at any time of the survey, in spite of having agreed to participate was emphasized to them. When the selected person who lived in the house was not available at the time of visiting the house, additional two visits were done to the house at times that he/she was expected to be available. In cases where the selected study unit could not be contacted even after three visits, the study unit was considered as a non-respondent.

In instances where the selected study unit was found to be deceased or not eligible to be included in the study, the principal investigator conducted the process of random sampling described above and selected another study unit to be included.

\section{Statistical analysis}

Statistical analysis was done by using SPSS version 20.0. The summary component scores of KDQOL-SF was non-normally distributed indicating a skewed distribution. Thus non-parametric tests were used in the bivariate analysis (Mann-Whitney $U$ test and Spearman's $r$ correlation) when determining the association between kidney, physical and mental summary components and some selected factors. A $p$ value of less than 0.05 was considered statistically significant. The following variables were analyzed with the each of the summary components; age, gender, education level, income status, employment status, the presence of comorbidities, CKD stage, symptom burden, presence of depression and Psychological distress. In order to explore how each socio demographic, as well as disease related characteristics, influence the HRQOL when the effects of other factors are controlled, multiple linear regression analysis was performed. Only the variables which had probability value of less than 0.2 in the univatiate linear regression analysis were included as independent variables in the multiple linear regression analysis. Normality of residuals was assessed using normal P-P plot while homoscedasticity was assessed using a scatter plot. The residuals were normally distributed and there was no evidence of heteroscedasticity. Evidence of outliers was assessed by Cook's distance score and a score of less than 'one' was considered appropriate. Multi-collinearity was assessed using the Variance Inflation Factor (VIF), which should be less than 'four'. The Cook's distance was 0.026 and the VIF score was less than two.

\section{Results}

Out of 1174 participants selected to be included in the study, 95 (8.1\%) did not participate in the study giving a response rate of $91.9 \%$. Of the 95 non-respondents, 69 (5.9\%) were not contactable even after three consecutive visits and $16(1.4 \%)$ didn't consent to participate for the study. Ten $(0.8 \%)$ completed less than half of the questionnaire due to various disturbances to the interview.

The mean age of the study population was 58.3 years (SD 10.7). There was a preponderance of males among the study population $(63.1 \%, N=681)$. The majority of participants was in the later stages, stage 4 or beyond, of CKD $(n=820 ; 75.9 \%)$. The 38 participants (3.5\%), with stage 5 of the disease and were undergoing dialysis, were on haemodialysis (Table 1). Chronic Kidney Disease of Unknown origin was the cause for the CKD in most of the study population $(n=471 ; 43.7 \%)$. The second most common was hypertension $(n=347 ; n=32.2 \%)$. The symptom burden score was assessed using CKDSI-Sri Lanka instrument and the median symptom burden score was 35.0 (IQR 20.0-49.0) while the mean score was 35.8 (SD 20.0). The median total monthly household income for the total study population was Rs.4000 (IQR 3000-7000), and the mean income was 6755.9 (SD 7492).

In the KDSC, symptom/problem domain (72.7; IQR 58.3-81.8), effects of kidney disease (75.0; IQR 59.387.5) and hospital staff encouragement (75.0; IQR 75.075.0) domains had median scores above 70.0 while the burden of kidney disease had the lowest median score (31.2; IQR 25.0-43.7). Median scores of all the four domains in the PCS had the scores below 50.0. The highest median score was for the pain domain (42.5; IQR 20.0$50.0)$ while the lowest was for the role-physical (0.0; IQR 22.5-45.0). Except the domain role-emotion (0.0; IQR 25.0-62.5), all the other domains in the MCS, had their median scores 50.0 or close to 50.0 (Table 2).

Kidney Disease Summary Component score (KDSC) (58.4; IQR 54.2-63.4), was higher than the summary scores of Physical Component Summary Score (PCS) (35.0; IQR 26.2-41.9) and Mental Component Summary Score (MCS) (58.4; IQR 54.2-63.4) (Table 3). Both 
Table 1 Socio Demographic characteristics

\begin{tabular}{|c|c|c|}
\hline Feature & Frequency $(\boldsymbol{N}=1079)$ & Percentage \\
\hline \multicolumn{3}{|l|}{ Age categories } \\
\hline $18-40$ & 50 & 4.6 \\
\hline $41-60$ & 558 & 51.7 \\
\hline$>60$ & 471 & 43.7 \\
\hline \multicolumn{3}{|l|}{ Gender } \\
\hline Male & 681 & 63.1 \\
\hline Female & 398 & 36.9 \\
\hline \multicolumn{3}{|l|}{ CKD stage } \\
\hline Early stages & 259 & 24.0 \\
\hline Stage IV & 629 & 58.3 \\
\hline Stage V & 153 & 14.2 \\
\hline Dialysis & 38 & 3.5 \\
\hline \multicolumn{3}{|l|}{ Comorbidities } \\
\hline Negative & 308 & 28.5 \\
\hline Positive & 771 & 71.5 \\
\hline \multicolumn{3}{|c|}{ Employment status } \\
\hline Not employed & 701 & 65.0 \\
\hline Employed & 378 & 35.0 \\
\hline \multicolumn{3}{|l|}{ Depression } \\
\hline Negative & 375 & 34.8 \\
\hline Positive & 704 & 65.2 \\
\hline \multicolumn{3}{|c|}{ Psychological distress } \\
\hline Negative & 267 & 24.7 \\
\hline Positive & 812 & 75.3 \\
\hline
\end{tabular}

KDSC $(r=-0.066)$ and PCS $(r=-0.082)$ scores showed a slight, but statistically significant, negative correlation with the age. Even though strength of association was slight $(r=0.086)$, KDSC and MCS scores had significant $(p<0.05)$ positive correlation with the education status. The income was significantly positively correlated with all three summary components while the CKD stage was significantly negatively correlated with the same. Both males and females had the median scores equal $(p>$ $0.05)$ in all the three summary scores. Currently being employed, screening positive for both depression and psychological distress were significantly $(p<0.001)$ associated with low HRQOL in all the summary scores (Table 4).

In order to explore how each socio demographic, as well as disease related characteristics, influenced the HRQOL of CKD when the effects of other factors are controlled, multiple linear regression analysis was performed. Age and sex were not significant predictors of either KDSC, PCS or MCS $(p>0.05)$. Education level was a significant predictor $(p<0.05)$ of higher scores of both $\operatorname{KDSC}(\beta=0.535)$ and MCS $(\beta=0.870)$, while the being employed was a significantly associated with higher scores of both $\operatorname{KDSC}(\beta=1.394)$ and PCS $(\beta=$ 1.966). Advanced stages of CKD, being positive for depression and being positive for psychological distress were significantly associated with low HRQOL in all the three summary component scores (Table 5).

\section{Discussion}

In the present study, the HRQOL of the study population was assessed using a locally validated KDQOL $\mathrm{SFT}^{\mathrm{M}}$. This is the first study in Sri Lanka which assessed the HRQOL of a community severely crippled by CKDu, and revealed that HRQOL among these population was severely compromised.

The KDQOL-SF ${ }^{\mathrm{sm}}$ is a popular tool that has been used to assess HRQOL among CKD patients by researchers the world over $[9,23]$. The KDSC, PCS and MCS in the present study were 58.7 (SD 7.7), 35.5 (SD 15.0) and 39.6 (SD 12.3) respectively, indicating that the HRQOL of these CKD patients in the rural community of Anuradhapura is poor. According to Mujais et al. (2009) who assessed the HRQOL of CKD patients in North America the mean KDSC, PCS and MCS scores were 74.6 (SD 13.6), 39.5 (10.6) and 49.8 (10.4) respectively. Except the KDSC, the scores of PCS and MC in the above study was almost similar to the findings of our study indicating that the HRQOL of CKD patients is compromised even in superior socio-economic and health contexts. This was further reiterate by the findings of Yusop et al. (2013) [23]. He assessed HRQOL of the CKD patients in Malaysia and the PCS (39.6; SD 8.6) and the MCS (45.0; SD 8.6) were almost similar to our findings.

Over the last few decades HRQOL strategies were mainly focusing on cancer patients, but studies have shown that patients with other life threatening conditions also experience a similar degree of effect to HRQOL [24]. Evidence indicate that both physical and mental distress experienced by patients dying from renal failure, could be more distressing than cancer [25]. Chronic kidney disease patients suffer from both physical and psychological symptoms which may emerge at different stages during the course of the disease [26]. Jang et al. (2019) assessed the HRQOL of patients with severe chronic obstructive pulmonary disease (COPD) using SF 36 study instrument and the PCS and MCS were 56.7 and 69.5 indicating that the HRQOL of CKD patients is much worse compared to COPD [27]. Similarly two international studies done to assess the HRQOL of stroke [28] and chronic heart failure [29] revealed that the stroke patients had relatively low HRQOL and chronic heart failure patients had a similar HRQOL when compared to the results of our study participants. Mahesh et al., (2017) conducted three separate studies to assess the HRQOL of stroke [28], myocardial infarction [30] and COPD [31] patients in Sri Lanka 
Table 2 Distribution of the QOL Domain Scores of the Study Population as Measured By KDQOL SF ${ }^{\mathrm{TM}}$

\begin{tabular}{|c|c|c|c|c|c|}
\hline Domains & Median & IQR & Mean & SD & Range \\
\hline \multicolumn{6}{|c|}{ Kidney Disease Specific Component } \\
\hline Symptom/problem domain & 72.7 & $58.3-81.8$ & 69.0 & 18.0 & $2.1-100.0$ \\
\hline Effects of kidney disease & 75.0 & $59.3-87.5$ & 73.5 & 19.0 & $6.2-100.0$ \\
\hline Burden of kidney disease & 31.2 & $25.0-43.7$ & 36.8 & 16.1 & $0.0-100.0$ \\
\hline Work status & 50.0 & $50.0-50.0$ & 50.5 & 10.4 & $0.0-100.0$ \\
\hline Cognitive function & 66.6 & $53.3-80.0$ & 65.5 & 17.1 & $0.0-100.0$ \\
\hline Quality of social interaction & 60.0 & $53.3-60.0$ & 57.9 & 11.8 & $0.0-100.0$ \\
\hline Sexual function $(n=625)$ & 50.0 & $25.0-100.0$ & 53.4 & 36.7 & $0.0-100.0$ \\
\hline Sleep & 52.5 & $40.0-62.5$ & 52.6 & 15.8 & $10.0-97.5$ \\
\hline Social support & 66.6 & $33.3-100.0$ & 66.1 & 25.9 & $0.0-100.0$ \\
\hline Hospital staff encouragement & 75.0 & $75.0-75.0$ & 71.6 & 14.2 & $25.0-100.0$ \\
\hline Patient satisfaction & 50.0 & $50.0-50.0$ & 47.4 & 11.3 & $16.7-83.3$ \\
\hline Overall Health & 50.0 & $40.0-60.0$ & 50.8 & 17.2 & $0.0-100.0$ \\
\hline \multicolumn{6}{|l|}{ Physical Component Domains } \\
\hline Physical functioning & 40.0 & $0.0-50.0$ & 41.3 & 24.0 & $0.0-100.0$ \\
\hline Role - physical & 0.0 & $22.5-45.0$ & 25.7 & 42.3 & $0.0-100.0$ \\
\hline Pain & 42.5 & $20.0-50.0$ & 36.2 & 17.0 & $0.0-100.0$ \\
\hline General health & 30.0 & $44.0-52.0$ & 37.6 & 19.6 & $5.0-90.0$ \\
\hline \multicolumn{6}{|l|}{ Mental Component Domains } \\
\hline Emotional well-being & 48.0 & $0.0-33.3$ & 48.1 & 9.7 & $8.0-84.0$ \\
\hline Role - emotional & 0.0 & $25.0-62.5$ & 23.1 & 32.8 & $0.0-100.0$ \\
\hline Social function & 50.0 & $40.0-50.0$ & 42.1 & 22.4 & $0.0-100.0$ \\
\hline Energy/fatigue & 50.0 & $25.0-75.0$ & 44.8 & 12.2 & $0.0-85.0$ \\
\hline Change in Health & 50.0 & $25.0-75.0$ & 52.10 & 29.9 & $0.0-100.0$ \\
\hline
\end{tabular}

using SF 36. All eight domain scores of PCS and MCS among myocardial infarction patients were superior to the respective domain scores in our study. Furthermore, among COPD patients, except the general health, physical functioning, energy/fatigue and emotional wellbeing, the other four domains had superior domain scores compared to CKD. Compared to the CKD patients, general health, physical functioning, emotional well-being and social functioning domain scores were low among the stroke patients. This indicate that compared to the three conditions studied by Mahesh et al., stroke, COPD and myocardial infarction, CKD patients had poor HRQOL in relations to pain and physical and emotional role limitations.
In the present study the KDSC was significantly higher compared to the PCS and MCS. A similar finding was evident in the multi country study done by Mujais et al., (2009), where the relatively higher scores were obtained for the domains of the Kidney Disease Specific Component [9]. It could be due to the fact that the scores of the disease specific component of the study tool is only sensitive to the severity of the disease, whereas the generic component scores of the study tool (physical and mental component) are sensitive not only to the severity of the disease but also to multiple other socio-economic factors, which are unfavorable for the CKD patients in a rural community with a poor socio-economical background such as the Anuradhapura district.

Table 3 Correlation between QOL domain scores and some selected factors

\begin{tabular}{lllllllll}
\hline Domain & Mean (SD) & Median & IQR & Age $^{\mathrm{b}}$ & Education level $^{\mathrm{b}}$ & Income $^{\mathrm{b}}$ & CKD stage $^{\mathrm{b}}$ & Symptom burden $^{\mathrm{b}}$ \\
\hline Kidney Disease Summary Component & $58.7(7.7)$ & 58.4 & $54.2-63.4$ & $-0.066^{\mathrm{a}}$ & $0.086^{\mathrm{a}}$ & $0.180^{\mathrm{a}}$ & $-0.122^{\mathrm{a}}$ & $0.066^{\mathrm{a}}$ \\
Physical Component Summary Score & $35.5(15.0)$ & 35.0 & $26.2-41.9$ & $-0.082^{\mathrm{a}}$ & 0.052 & $0.152^{\mathrm{a}}$ & $-0.327^{\mathrm{a}}$ & $0.101^{\mathrm{a}}$ \\
Mental Component Summary Score & $39.6(12.3)$ & 39.0 & $34.6-42.8$ & -0.047 & $0.077^{\mathrm{a}}$ & $0.155^{\mathrm{a}}$ & $-0.346^{\mathrm{a}}$ & 0.038 \\
\hline
\end{tabular}


Table 4 Association between kidney, physical and mental summary components and some selected factors

\begin{tabular}{|c|c|c|c|c|c|c|c|c|c|}
\hline \multirow[t]{2}{*}{ Characteristic } & \multicolumn{3}{|c|}{ Kidney Disease Summary Component } & \multicolumn{3}{|c|}{ Physical Component Summary Score } & \multicolumn{3}{|c|}{ Mental Component Summary Score } \\
\hline & Median & IQR & $p$ value $^{a}$ & Median & IQR & $\boldsymbol{p}$ value $^{\mathbf{a}}$ & Median & IQR & $\boldsymbol{p}$ value $^{\mathbf{a}}$ \\
\hline \multicolumn{10}{|l|}{ Gender } \\
\hline Male & 58.5 & $54.2-63.7$ & 0.470 & 35.0 & $26.2-40.9$ & 0.443 & 38.8 & $34.8-42.2$ & 0.470 \\
\hline Female & 58.2 & $54.3-63.1$ & & 36.2 & $25.0-43.1$ & & 39.1 & $33.5-43.7$ & \\
\hline \multicolumn{10}{|l|}{ Employment } \\
\hline Employed & 60.4 & $56.0-65.0$ & $<0.001$ & 36.3 & $30.0-45.6$ & $<0.001$ & 39.5 & $36.2-43.3$ & $<0.001$ \\
\hline Not employed & 57.6 & $53.3-62.5$ & & 33.7 & $23.7-40.6$ & & 38.4 & $32.3-42.4$ & \\
\hline \multicolumn{10}{|l|}{ Comorbidities } \\
\hline Present & 58.2 & $53.8-62.8$ & 0.002 & 35.0 & $25.0-42.5$ & 0.539 & 39.0 & $34.0-43.0$ & 0.515 \\
\hline Absent & 59.6 & $55.3-65.2$ & & 35.0 & $27.5-41.1$ & & 39.1 & $35.5-42.5$ & \\
\hline \multicolumn{10}{|l|}{ Depression } \\
\hline Positive & 56.4 & $52.6-60.6$ & $<0.001$ & 33.7 & $23.7-40.0$ & $<0.001$ & 37.9 & $30.5-41.3$ & $<0.001$ \\
\hline Negative & 63.3 & $58.5-67.9$ & & 36.2 & $30.0-48.1$ & & 40.1 & $37.1-46.1$ & \\
\hline \multicolumn{10}{|c|}{ Psychological distress } \\
\hline Positive & 57.2 & $53.3-61.9$ & $<0.001$ & 33.7 & 23.7-39.4 & $<0.001$ & 38.2 & $32.1-41.3$ & $<0.001$ \\
\hline Negative & 63.5 & $57.8-68.5$ & & 41.2 & $32.5-57.5$ & & 41.3 & $37.7-52.8$ & \\
\hline
\end{tabular}

${ }^{\mathrm{a} A s s o c i a t i o n}$ tested by Mann-Whitney $\mathrm{U}$ test

Table 5 Independent predictors of QOL using multiple linear regression

\begin{tabular}{|c|c|c|c|c|c|c|}
\hline & \multicolumn{2}{|c|}{ Kidney Component Summary Score } & \multicolumn{2}{|c|}{ Physical Component Summary Score } & \multicolumn{2}{|c|}{ Mental Component Summary Score } \\
\hline & Beta coefficient & $95 \% \mathrm{Cl}$ & Beta coefficient & $95 \% \mathrm{Cl}$ & Beta coefficient & $95 \% \mathrm{Cl}$ \\
\hline Age & 0.02 & -0.02 to 0.059 & -0.005 & -0.08 to 0.07 & NA & \\
\hline \multicolumn{7}{|l|}{ Gender } \\
\hline Male & NA & & NA & & NA & \\
\hline Female & NA & & NA & & NA & \\
\hline Education level & $0.52^{\mathrm{a}}$ & 0.08 to 0.95 & 0.632 & -0.22 to 1.49 & $0.84^{\mathrm{a}}$ & 0.16 to 1.53 \\
\hline \multicolumn{7}{|l|}{ Employment } \\
\hline Employed & $1.27^{\mathrm{a}}$ & 0.30 to 2.23 & $1.94^{\mathrm{a}}$ & 0.05 to 3.83 & 1.04 & -0.45 to 2.53 \\
\hline Not employed & 1 & & 1 & & 1 & \\
\hline Income (in thousands) & 0.05 & -0.08 to 0.07 & $0.15^{\mathrm{a}}$ & 0.03 to 0.27 & $0.12^{\mathrm{a}}$ & 0.03 to 0.22 \\
\hline \multicolumn{7}{|l|}{ Comorbidities } \\
\hline Present & -0.38 & -1.27 to 0.52 & NA & & NA & \\
\hline Absent & 1 & & NA & & NA & \\
\hline CKD stage & $-1.38^{\mathrm{a}}$ & -1.92 to -0.82 & $-6.37^{a}$ & -7.46 to -5.28 & $-6.31^{\mathrm{a}}$ & -7.19 to -5.44 \\
\hline \multicolumn{7}{|l|}{ Depression } \\
\hline Positive & $-5.31^{\mathrm{a}}$ & -6.25 to -4.37 & $-2.16^{\mathrm{a}}$ & -4.01 to -0.31 & $-3.35^{\mathrm{a}}$ & -4.8 to -1.8 \\
\hline Negative & 1 & & 1 & & 1 & \\
\hline \multicolumn{7}{|l|}{ Psychological distress } \\
\hline Positive & $-3.31^{\mathrm{a}}$ & -4.34 to -2.28 & $-9.30^{\mathrm{a}}$ & -11.3 to -7.2 & $-6.02^{\mathrm{a}}$ & -7.6 to -4.3 \\
\hline Negative & 1 & & 1 & & 1 & \\
\hline Symptom burden & NA & & $0.06^{\mathrm{a}}$ & 0.02 to 0.10 & NA & \\
\hline
\end{tabular}


It was surprising to note that in the present study, the gender of the patients was not a significantly predictor of HRQOL. This was contrary to the findings of Mujais et al. (2009) where female gender was a significant predictor of low HRQOL [9]. Unemployment due to the disease, difficulty in engaging in the current occupation and inability to perform the role expected from society, is more common among males in the local setting, which could lead to poor HRQOL among male CKD patients in the study setting.

Higher education level, being employed and higher income were significant independent predictors of higher summary component scores. This indicate that in general, the improvement of socio-economic and educational aspects is associated with better quality of life among these patients. Further, social acceptance, being able to perform social responsibilities and self-esteem which are directly linked to the employment status, income and education status of an individual $[32,33]$ and they also could have contributed to the superior HRQOL of patients with this subset of the study population.

CKD stage was a significant independent predictor of scores in all three summary scores, but the magnitude of association was much higher in PCS and MCS, compared to the association between CKD stage and KDSC. One would expect the KDSC, which assess the kidney disease specific HRQL, to show the highest association with CKD stage compared to others as reported in several studies internationally $[9,34]$. However, a similar finding to the current study has been observed in the study conducted by Perlman et al., (2005) and the authors have ascribed the results to the narrow range of glomerular filtration rate (GFR) in their study [35], which could be the reason in the current study as well.

The results indicate that the symptom burden significantly affects the HRQOL related to the physical and mental health status in CKD patients (PCS and MCS). This picture was further reinforced by the fact that depressed and psychologically distressed patients had significantly low HRQOL scores in all three summary scores. This finding has been reiterated in the global literature as well. Symptom burden [36] and mental health status [37] were stated as key determinants of HRQOL of CKD patients. This highlights an important finding of clinical importance, that is if the service providers to improve the HRQOL of patients, not only physical symptom alleviating measures but also measures to improve the mental health status of patients should also be considered.

Our study has some limitations. Firstly, the HRQOL assessment did not employ a control group due to feasibility and logistic constraints. Inclusion of a control group could have enabled comparison between the two groups to produce more meaningful interpretation.
Secondly, some of the information related to HRQOL is considered to be sensitive in nature and the fact that this information was obtained utilizing an intervieweradministered questionnaire could have led to some under-reporting in the assessment of HRQOL, though many measures were taken to minimize this issue. Finally, The CKD stage in this study was calculated using secondary data. Biochemical assessment of study units was not economically feasible in the study.

\section{Conclusion}

The HRQOL of the CKD patients in this rural Sri Lankan population was found to be poor. Higher education status and being employed were important predictors of higher HRQOL, while advanced stages of CKD, being positive for depression and being positive for psychological distress were significantly associated with low HRQOL. The study recommends numerous measures to improve the HRQOL of these patients. Periodical screening of the CKD patients for depression and psychological distress and measures to alleviate symptom burden seem to be important and practical aspects which can be implemented to improve the overall quality of life of these patients.

\section{Supplementary information}

Supplementary information accompanies this paper at https://doi.org/10. 1186/s12955-020-01369-1.

Additional file 1. Supplementary material Number of CKD patients

selected from each $\mathrm{MOH}$ area for the study.

\section{Abbreviations}

CES-D: Center for Epidemiological Studies - Depression scale; CKD: Chronic Kidney Disease; CKDSI-Sri Lanka: Chronic Kidney Disease Symptom Index Sri Lanka; COPD: Chronic Obstructive Pulmonary Disease; GFR: Glomerular Filtration Rate; GHQ-12: General Health Questionnaire 12; HRQOL: Health Related Quality of Life; IQR: Inter Quartile Range; KDQOL-SF: Kidney Disease Quality of Life - Short Form; KDSC: Kidney Disease Summary Component; MCS: Mental Component Summary; MOH: Medical Officer of Health; NCP: North Central Province; PCS: Physical Component Summary; SD: Standard Deviation; WHOQOL: World Health Organization Quality of Life Group

\section{Acknowledgements}

Authors acknowledge Palitha Bandara and Asanga Ranasinghe, for the support rendered during the study. The study was funded by the Ministry of Health, Sri Lanka.

\section{Authors' contributions}

$\mathrm{SS}^{1}$, NG, PP, SK: Research idea, study design. SS ${ }^{1}, \mathrm{NG}, \mathrm{SK}, \mathrm{SS}^{2}, \mathrm{RK}, \mathrm{PK}$ : statistical analysis and drafting of the manuscript. SS ${ }^{1}, \mathrm{NG}, \mathrm{PP}, \mathrm{SK}, \mathrm{SS}{ }^{2}, \mathrm{RK}, \mathrm{PK}$ : data analysis/interpretation. The authors read and approved the final manuscript.

\section{Funding}

This study was funded by the Ministry of Sri Lanka.

Availability of data and materials

The datasets used and/or analysed during the current study are available from the corresponding author on reasonable request. 


\section{Ethics approval and consent to participate}

The study is in accordance with Helsinki Declaration. The study protocol has been approved by the Ethics Committee of Colombo Medical Faculty (EC15-081). Participants gave their informed consent.

\section{Consent for publication}

Not applicable.

\section{Competing interests}

The authors declare that they have no competing interests.

\section{Author details}

${ }^{1}$ Epidemiology Unit, Ministry of Health, Colombo, Sri Lanka. ${ }^{2}$ World Health Organization, Colombo, Sri Lanka. ${ }^{3}$ Australian Centre for Health Service Innovation, Queensland University of Technology, Brisbane, Australia. ${ }^{4}$ North Central Provincial Directors Office, Anuradhapura, Sri Lanka.

\section{Received: 18 April 2019 Accepted: 16 April 2020}

\section{Published online: 23 April 2020}

\section{References}

1. Group W. The World Health Organization quality of life assessment (WHOQOL): position paper from the World Health Organization. Soc Sci Med. 1995;41(10):1403-9.

2. Ferrans CE. Definitions and conceptual models of quality of life. Outcomes Assess Cancer. 2005:9:14-30.

3. O'shaughnessy DV, Elder GJ. Patient-level outcomes: the missing link. Nephrology. 2009;14(4):443-51.

4. Medical Statistics Unit. Annual health bulletin: medical statistics unit, Ministry of Sri Lank; 2017. Available from: http://www.health.gov.lk/moh_ final/english/public/elfinder/files/publications/AHB/2017/AHS2017.pdf.

5. Medical Statistics Unit. Annual health bulletin: medical statistics unit, Ministry of Sri Lank; 2012. Available from: http://www.health.gov.lk/moh_ final/english/public/elfinder/files/publications/AHB/Annual\%20Health\%2 OBulletin\%20-\%202012.pdf.

6. Senanayake S. Chronic kidney disease in Sri Lanka: a glimpse into lives of the affected. J Coll Community Physicians Sri Lanka. 2018:24:2.

7. Senanayake S, Gunawardena N, Palihawadana P, Suraweera C, Karunarathna R, Kumara P. Depression and psychological distress in patients with chronic renal failure: prevalence and associated factors in a rural district in Sri Lanka. J Psychosom Res. 2018;112:25-31.

8. Rebollo P, González M, Bobes J, Saiz P, Ortega F. Interpretation of healthrelated quality of life of patients on replacement therapy in end-stage renal disease. Nefrologia. 2000;20(5):431-9.

9. Mujais SK, Story K, Brouillette J, Takano T, Soroka S, Franek C, et al. Healthrelated quality of life in CKD patients: correlates and evolution over time. Clin J Am Soc Nephrol. 2009;4(8):1293-301.

10. Tsai Y-C, Hung C-C, Hwang S-J, Wang S-L, Hsiao S-M, Lin M-Y, et al. Quality of life predicts risks of end-stage renal disease and mortality in patients with chronic kidney disease. Nephrol Dial Transplant. 2009;25(5):1621-6.

11. DeOreo PB. Hemodialysis patient-assessed functional health status predicts continued survival, hospitalization, and dialysis-attendance compliance. Am J Kidney Dis. 1997;30(2):204-12.

12. Levey AS, Coresh J, Bolton K, Culleton B, Harvey KS, Ikizler TA, et al. K/DOQ clinical practice guidelines for chronic kidney disease: evaluation, classification, and stratification. Am J Kidney Dis. 2002;39(2 SUPPL):1.

13. Wanigasuriya K. Aetiological factors of chronic kidney disease in the north Central Province of Sri Lanka: a review of evidence to-date; 2012.

14. Jayasekara J, Dissanayake D, Adhikari S, Bandara P. Geographical distribution of chronic kidney disease of unknown origin in north central region of Sri Lanka. Ceylon Med J. 2013;58(1):6-10.

15. Medical Statistics Unit. Annual health bulletin - 2016. Colombo: Medical statistics unit, Ministry of Sri Lanka; 2016

16. Athuraliya $T$, Abeysekera $D$, Amerasinghe $\mathrm{PH}$, Kumarasiri $\mathrm{P}$, Dissanayake $\mathrm{V}$. Prevalence of chronic kidney disease in two tertiary care hospitals: high proportion of cases with uncertain aetiology. Ceylon Med J. 2009:54:1.

17. Jayasinghe S. Chronic kidney disease in rural areas of Sri Lanka: an evolving catastrophe needing an urgent response; 2014.

18. Senanayake S, Gunawardena N, Palihawadana P, Kularatna S, Peiris T. Validity and reliability of the Sri Lankan version of the kidney disease quality of life questionnaire (KDQOL-SF ${ }^{\mathrm{TM}}$ ). Health Qual Life Outcomes. 2017;15(1):119.
19. De Silva V, Ekanayake S, Hanwella R. Validity of the Sinhala version of the Centre for Epidemiological Studies Depression Scale (CES-D) in out-patients. Ceylon Med J. 2014;59:1.

20. Abeysena $H$, Jayawardana $P$, Peiris $U$, Rodrigo A. Validation of the Sinhala version of the 12-item general health questionnaire. J Postgrad Inst Med. 2014;1:1.

21. Senanayake S, Gunawardena N, Palihawadana P. Development of the chronic kidney disease symptom index-Sri Lanka; a symptom assessment instrument for chronic kidney disease patients. J Postgrad Inst Med. 2017:4:1.

22. Department of Census and Statistics. Census of population and housing 2012 (north Central Province): Department of Census and Statistics; 2016. Available from: http://www.statistics.gov.lk/PopHouSat/CPH2011/Pages/ Activities/Reports/NCP.pdf.

23. Yusop NBM, Mun CY, Shariff ZM, Huat CB. Factors associated with quality of life among hemodialysis patients in Malaysia. PLoS One. 2013:8(12):e84152.

24. Sepúlveda C, Marlin A, Yoshida T, Ullrich A. Palliative care: the World Health Organization's global perspective. J Pain Symptom Manag. 2002;24(2):91-6.

25. Solano JP, Gomes B, Higginson IJ. A comparison of symptom prevalence in far advanced cancer, AIDS, heart disease, chronic obstructive pulmonary disease and renal disease. J Pain Symptom Manag. 2006;31(1):58-69.

26. Lee SJ, Jeon J. Relationship between symptom clusters and quality of life in patients at stages 2 to 4 chronic kidney disease in Korea. Appl Nurs Res. 2015;28(4):e13-e9.

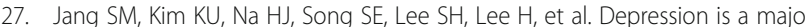
determinant of both disease-specific and generic health-related quality of life in people with severe COPD. Chronic Respir Dis. 2019:16: 1479972318775422

28. Mahesh P, Gunathunga M, Jayasinghe S, Arnold S, Liyanage S. Factors influencing pre-stroke and post-stroke quality of life among stroke survivors in a lower middle-income country. Neurol Sci. 2018;39(2):287-95.

29. Mommersteeg PM, Kupper N, Schoormans D, Emons W, Pedersen SS. Health-related quality of life is related to cytokine levels at 12 months in patients with chronic heart failure. Brain Behav Immun. 2010;24(4):615-22.

30. Mahesh P, Gunathunga M, Jayasinghe S, Arnold S, Haniffa R, De Silva A. Preevent quality of life and its influence on the post-event quality of life among patients with ST elevation and non-ST elevation myocardial infarctions of a premier province of Sri Lanka. Health Qual Life Outcomes. 2017;15(1):154

31. Mahesh P, Gunathunga W, Jayasinghe S, Arnold M, Croos V, De Silva S. Quality of life and its associated factors among patients with COPD before and after an exacerbation in Sri Lanka; 2018.

32. Frankham C, Richardson T, Maguire N. Psychological factors associated with financial hardship and mental health: a systematic review. Clin Psychol Rev. 2020;101832:1

33. Soelton M, Amalia D, Noermijati N, Wahyudiono B. Self-esteem: the levels of religiosity in job insecurity and stress in government company. In: 4th international conference on management, economics and business (ICMEB 2019). Jakarta: Atlantis Press; 2020.

34. Rocco MV, Gassman JJ, Wang S-R, Kaplan RM. Cross-sectional study of quality of life and symptoms in chronic renal disease patients: the modification of diet in renal disease study. Am J Kidney Dis. 1997;29(6):888-96.

35. Perlman RL, Finkelstein FO, Liu L, Roys E, Kiser M, Eisele G, et al. Quality of life in chronic kidney disease (CKD): a cross-sectional analysis in the renal research institute-CKD study. Am J Kidney Dis. 2005;45(4):658-66.

36. Weisbord SD. Symptoms and their correlates in chronic kidney disease. Adv Chronic Kidney Dis. 2007;14(4):319-27.

37. Kutner NG. Promoting functioning and well-being in older CKD patients: review of recent evidence. Int Urol Nephrol. 2008;40(4):1151.

\section{Publisher's Note}

Springer Nature remains neutral with regard to jurisdictional claims in published maps and institutional affiliations. 